\title{
Experimental investigation of the degree of weakening in structural notch area of 7075-T6 aluminum alloy sheet welded with the RFSSW method
}

\author{
Andrzej Kubit ${ }^{1, *}$, Magdalena Bucior $^{1}$, Dawid Wydrzyński ${ }^{1}$, and Lukasz Bąk ${ }^{2}$ \\ ${ }^{1}$ Faculty of Mechanical Engineering and Aeronautics, Department of Manufacturing Processes and Production Engineering, \\ Rzeszow University of Technology, Powstańców Warszawy 8, 35-959 Rzeszów, Poland \\ ${ }^{2}$ Faculty of Mechanical Engineering and Aeronautics, Department of Materials Forming and Processing, Rzeszow University of \\ Technology, Powstańców Warszawy 8, 35-959 Rzeszów, Poland
}

\begin{abstract}
The paper presents the methodology of the research determining the degree of weakening of the welded sheet obtained by the refill friction stir spot welding (RFSSW) method. The considered weakness is the effect of a structural notch resulting from penetration by the tool. RFSSW technology is a relatively new method of joining metals, which can successfully provide an alternative to resistance welding or riveting - traditionally used methods of joining thin-walled structures in the aerospace and automotive industries. The study presented in the paper focuses on the overlapping of sheet metal with 7075-T6 aluminum alloy combined in the configuration: $1.6 \mathrm{~mm}$ top sheet and $0.8 \mathrm{~mm}$ bottom sheet. Joints were assembled following the following process parameters: Welding time $1.5 \mathrm{~s}$, the tool plunge depth in the range of $1.5 \div 1.9 \mathrm{~mm}$, and the spindle speed of $2600 \mathrm{rpm}$. The analysis of the microstructure of joints revealed that along the edge of the tool path a structural notch is formed, the size and shape of which depend on the parameters applied. The paper describes the study consisting in punching the welded area along the formed notch in the upper sheet. The punching process was performed on a universal testing machine and the punching force was measured during the test. Based on the force value, the degree of sheet weakening in the notched area was determined. The smallest weakening was observed in joints made with the smallest tool depth, i.e. $1.5 \mathrm{~mm}$, whereas the biggest weakening was obtained for tool depth of 1.9 $\mathrm{mm}$. The load applied to the joints was equal to $5290 \mathrm{~N}$ and $7585 \mathrm{~N}$ respectively.
\end{abstract}

\section{Introduction}

The most commonly used materials in aircraft are aluminum alloys of the $2 \mathrm{XXX}[1]$ and $7 \mathrm{XXX}$ series [2, 3]. Main advantages of these alloys are their high strength and relatively low weight [4]. These properties have a significant role in the aviation industry because they reduce the weight of the aircraft and at the same time lower the operation costs. Aluminum alloys can be joined using various methods such as riveting, resistance welding [5] and adhesive bonding [6, 7]. Selecting the appropriate joining method depends on multiple factors, which include: the properties of joined alloys, geometric dimensions of the part (thickness of the joint elements) and the operational requirements.

Aircraft designs traditionally feature riveting as the main joining technique. The number of rivets used to join aircraft parts significantly increases the weight of the aircraft. An alternative joining method could be Refill Friction Stir Spot Welding (RFSSW) [8].

Considering the order of sleeve and pin movement, there are two different RFSSW methods. The article presents the variant in which the sleeve plunges into the joined material while the pin is responsible for pressing the material that was previously pushed out. Normally, the RFSSW process consists of four stages. The first stage consists in positioning the pin and sleeve on the top plane of the sheet metal joint. The clamping ring exerts constant pressure on the joined materials, which protects it from uncontrolled translation. Next the sleeve performs a rotational move and plunges into the material making it plastic and pushes it into the void formed by the receding pin. In the next stage, the pin plunges into the joint and the sleeve recedes upwards. The final stage consists of a quick positioning of the tool on the top surface of the metal sheet joint.

This is a relatively new technology, and therefore there are aspects of the process that are still under research $[2,9,10]$. The advantages of this method include: good mechanical properties, low energy consumption, the possibility of combining materials of different properties $[11,12]$. However, determining the correct welding parameters causes multiple problems. The quality of RFSSW spot welds depends on such

*Corresponding author: akubit@prz.edu.pl 
welding parameters as" plunge depth $[13,14]$, tool rotational speed $[9,14,15]$ and welding times $[9,14]$, which are a subject of analysis of numerous researches. Unfortunately, these articles offer no information regarding the degree of weakening of the welded sheet obtained by RFSSW method. It seems therefore important to carry out tests aimed at determining the relationship between process parameters and weakening of the weld joint.

The paper describes the study of punching the welded area along the notch formed in the upper sheet. The punching process was performed on a universal testing machine and the punching force was measured in the tests. Based on the force value, the degree of sheet weakening in the notched area was determined.

\section{Method}

This section presents the methodology for studying the weakening of a metal sheet joint that results from a structural notch and Thermo-mechanically Affected Zone (TMAZ) created during the welding process. The subject of the study was the RFSSW weld made in 7075T6 Alclad aluminum alloy sheet. The chemical composition of the alloy is the following: $\mathrm{Si}-0.4, \mathrm{Fe}-$ $0.5, \mathrm{Cu}-1.2 \div 2, \mathrm{Mn}-0.3, \mathrm{Mg}-2.1-2.9, \mathrm{Cr}-0.18 \div$ $0.35, \mathrm{Zn}-5.1 \div 6.1, \mathrm{Ti}-0.2$, other impurities: single 0.05 , total $0.15, \mathrm{Al}$ - rest. The joint was assembled on a HARMS WENDE machine using the tool presented in Fig. 1a.

a)

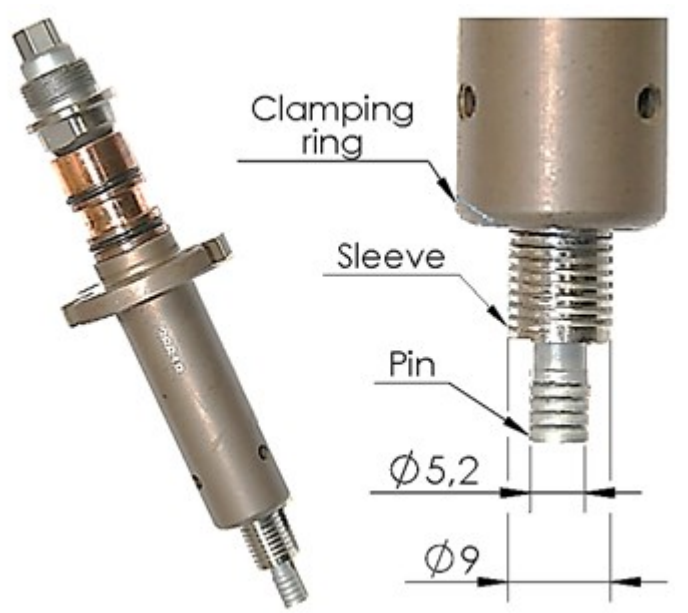

b)

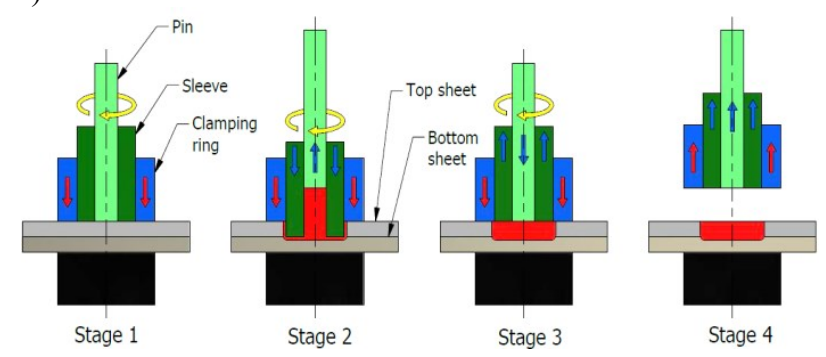

Fig. 1. Schematic illustration of the RFSSW processes (a) and a diagram of the constituent parts of the tools and their diameters (b).
The main parameters of the welding process are: tool rotational speed, tool plunge depth and plunging time.

The parameters in this study were selected on the basis of previous tests of the authors $[14,16]$. A constant tool rotational speed of $2600 \mathrm{rpm}$ and plunging time of $1.5 \mathrm{~s}$ were adopted in the study.

Because the size of the structural notch depends largely on the tool plunge depth, hence the tests comparing the joints made with the following depths: $1.5,1.7$ and 1.9 $\mathrm{mm}$.

Fig. 2 presents a lap joint used to determine the load carrying capacity of the joint and the weakening of the weld. The analyzed lap joint consisted of two pieces of metal sheet where the top one was $1.6 \mathrm{~mm}$ thick and the bottom one was $0.8 \mathrm{~mm}$ thick.
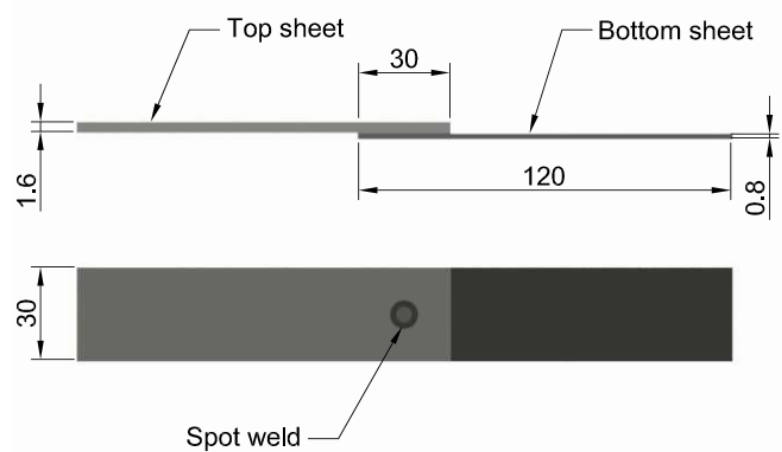

Fig. 2. The shape of the lap joint specimens used in the study.

The methodology of the study predicts weakening of only the top sheet in pure shear strength test. The lap joint in the presented configuration undergoes a tensile test, where the complex loading condition causes bending in the metal sheet. The requirement of maintaining an unbent state of the metal sheet joint after the strength test lead to the use of a special fixture that prevented bending of the metal sheet during loading, which is presented as a diagram in Fig. 3a, while a photograph of the test bench is presented in Fig. $3 \mathrm{~b}$. The strength tests were performed on a ZWICK Z100 strength test machine with a jaw translation speed of 5 $\mathrm{mm} / \mathrm{min}$. a)

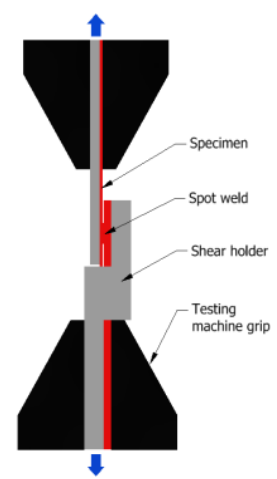

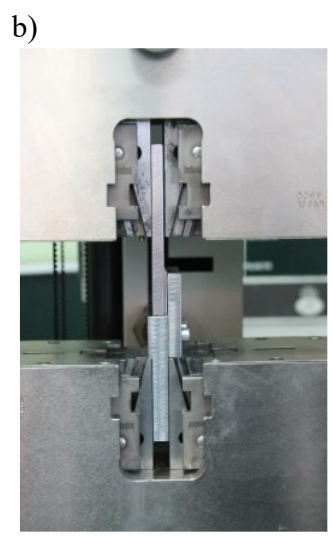

Fig. 3. Diagram of the fixture used to apply pure shearing force in the static strength tests (a) and a photograph of the fixture in the test bench (b). 
The primary assumption of the study was to determine the degree of weakening of weld along its circumference based on the punch force measurement around the stir area in a punch-matrix system for the top sheet, which is shown in Fig. $4 \mathrm{a}$, while $4 \mathrm{~b}$ presents the test bench and describes the parts of the set-up. The tests were conducted on a ZWICK Z50 strength test machine with a jaw translation speed of $10 \mathrm{~mm} / \mathrm{min}$. Besides measuring the ejection occurring in the weld area of the upper sheet, the force needed to punch through the solid sheet metal was also measured on the aforementioned test bench.

a)

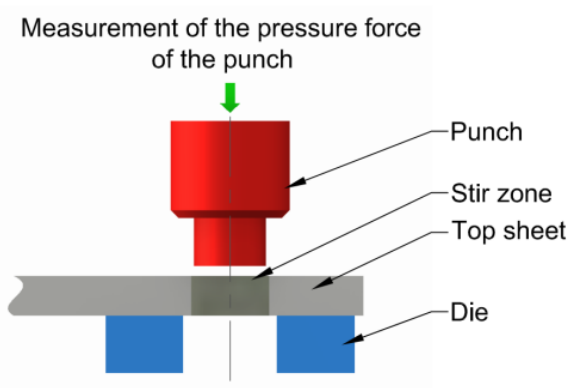

b)

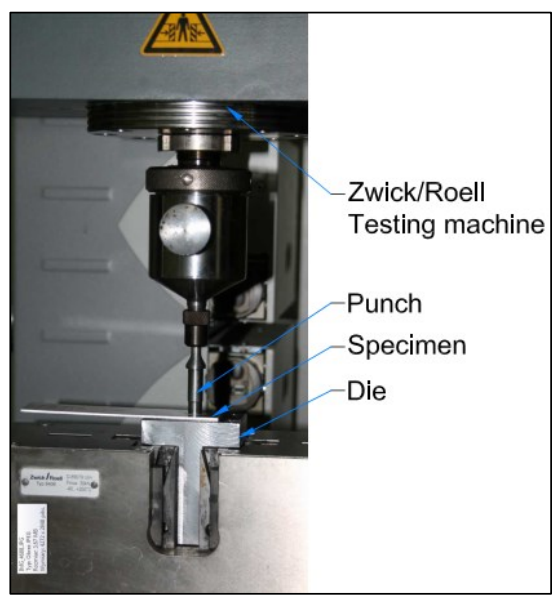

Fig. 4. Diagram presenting the operation concept of the test bench used to determine the degree of weld weakening near the structural notch (a) view of the test bench (b).

Microstructural examination of the RFSSW specimens was carried out using Nikon Epiphot 300 light microscope with NIS-Elements V2.3 software. Macroscopic examination was also conducted using Opta-Tech X2000 stereoscopic microscope. Metallographic specimens were prepared according to ASTM E407 [17] following the given procedure: the samples were first cut using Struers Accutom-50 precision machine and then mounted in StruersPolyfast resin using Struers LaboPress-3. The micro-sections were prepared in accordance with the following procedure: grinding with abrasive papers down to 1200 grit size and polishing using diamond suspensions $(9,6$, 3, $1 \mu \mathrm{m})$. Micro-sections were etched with Keller's reagent, composed of $2 \mathrm{ml}$ of $\mathrm{HF}, 3 \mathrm{ml}$ of HCL, and $5 \mathrm{ml}$ of HNO3 diluted in $190 \mathrm{ml}$ of distilled water, and the etching time was about $10 \mathrm{~s}$.

\section{Results and discussion}

After assembling the lap joint for each of the variants, selected samples were used as metallographic sections. The macrostructures of each tool plunge depth are presented in Fig. 5. The structure of the weld for every variant contains fine grains in comparison to the parent material. In some areas of the weld, plating can also be observed that results from the layered concentration near the base of the weld during process.

a)

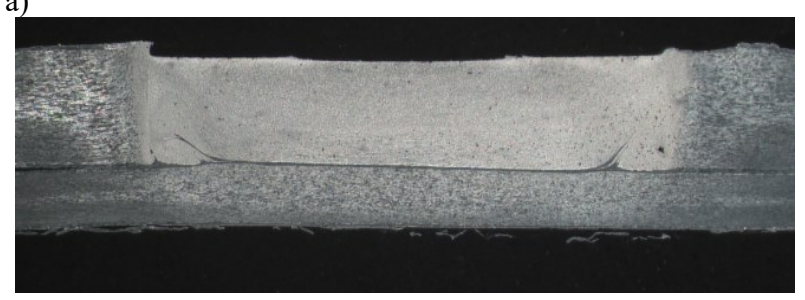

b)

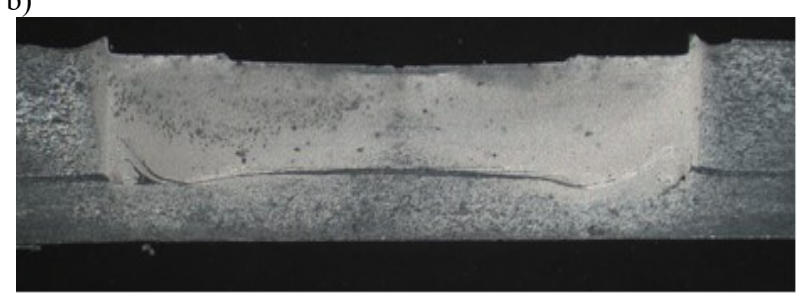

c)

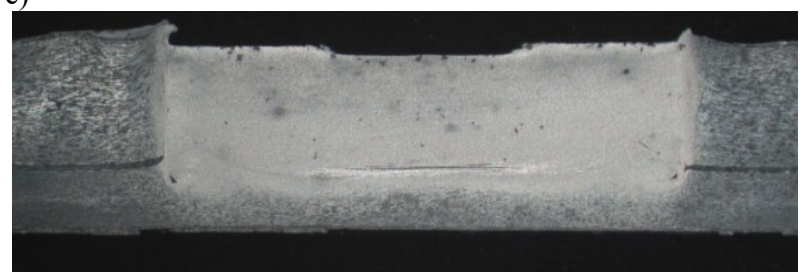

Fig. 5. The macrostructure of the welds created using different tool plunge depths: $1.5 \mathrm{~mm}$ (a), $1.7 \mathrm{~mm}$ (b) and $1.9 \mathrm{~mm}$ (c).

The macrostructure views of the joint showed that every variant included a structural notch on the circumference of the weld in the penetration area of the external part of the tool, more precisely, a 9-mm-wide cylinder. Fig. 6 shows the microstructure of selected welds to illustrate the weakening phenomena. Fig. 6a presents the microstructure of the $1.5 \mathrm{~mm}$ deep tool plunge and highlights critical areas.

While conducting the static shear strength test that used a fixture ensuring pure shear, a unique observation was made for the samples with a $1.9 \mathrm{~mm}$ tool plunge depth, where disintegration of the weld area and the upper sheet occurred, as shown in Fig. 7.

a)

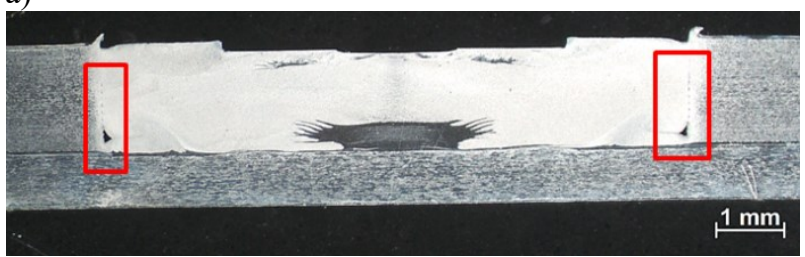


b)

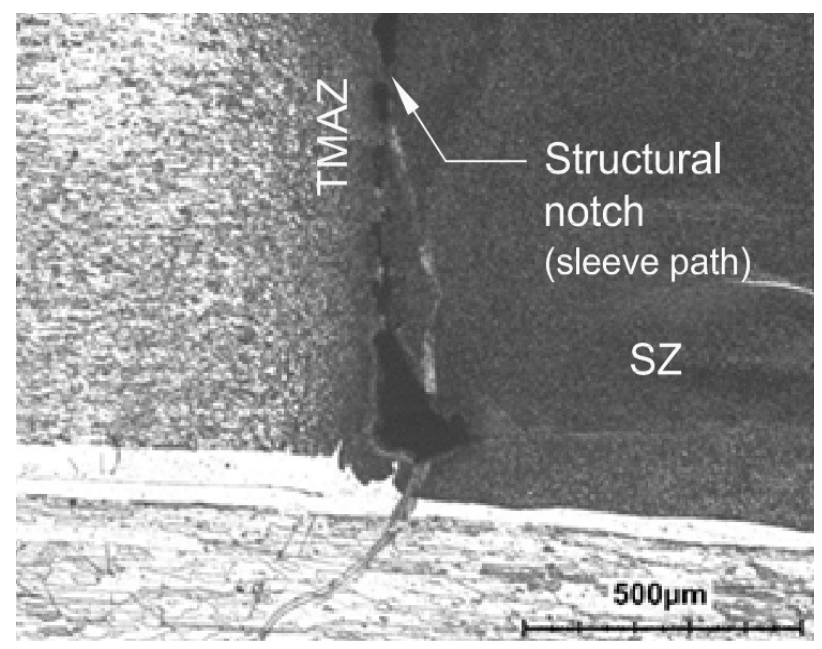

c)

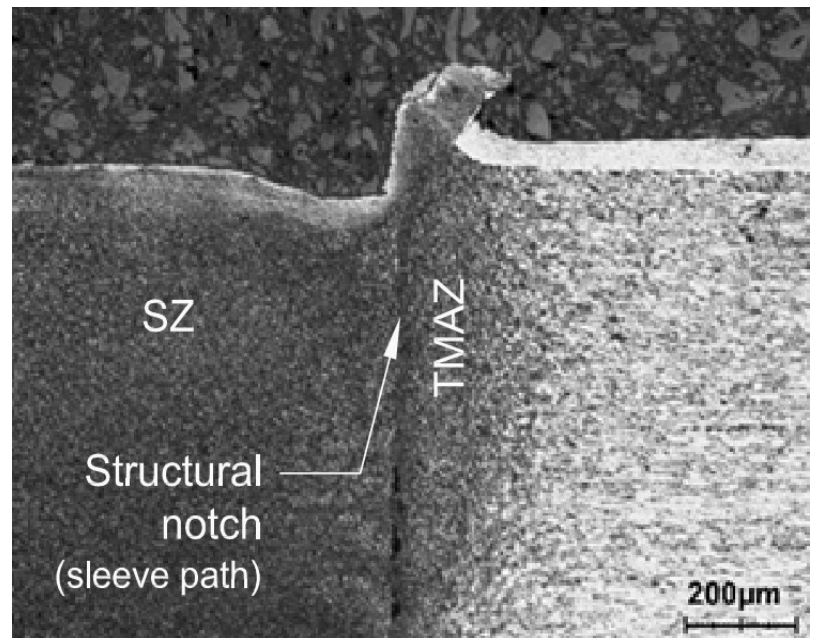

d)

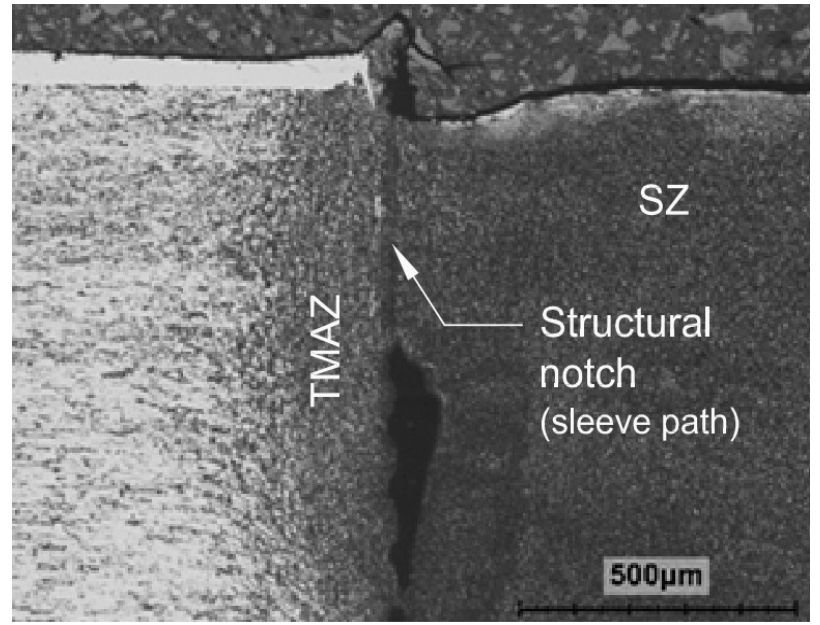

Fig. 6. The microstructure of the weld that highlights the structural notch area (a) and the microstructure showing the existence of structural notches for joints made with the following tool plunge depths: $1.5 \mathrm{~mm}(\mathrm{~b}), 1.7 \mathrm{~mm}$ (c) and $1.9 \mathrm{~mm}$ (d). Marked areas: SZ - Stir Zone, TMAZ - ThermoMechanically Affected Zone.

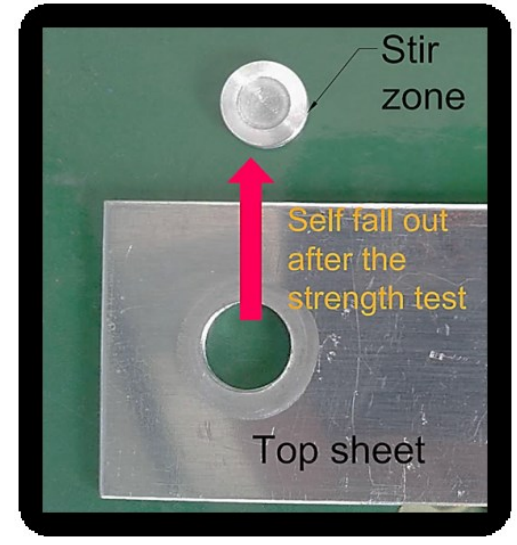

Fig. 7. The self fall out of the stir zone after the static shear strength test.

The ejection of the stir zone was conducted with three repetitions for each variant. The control for the analysis was the result of the punching test conducted on solid 1.6-mm-thick metal sheet on the aforementioned test bench. Fig. 8 presents sample curves for the stir zone ejection trials for each variant. Although the beginnings of the curves are similar, a tendency may be observed that the maximum force pushing out the stir zone decreases with an increase in the tool plunge depth during welding process.

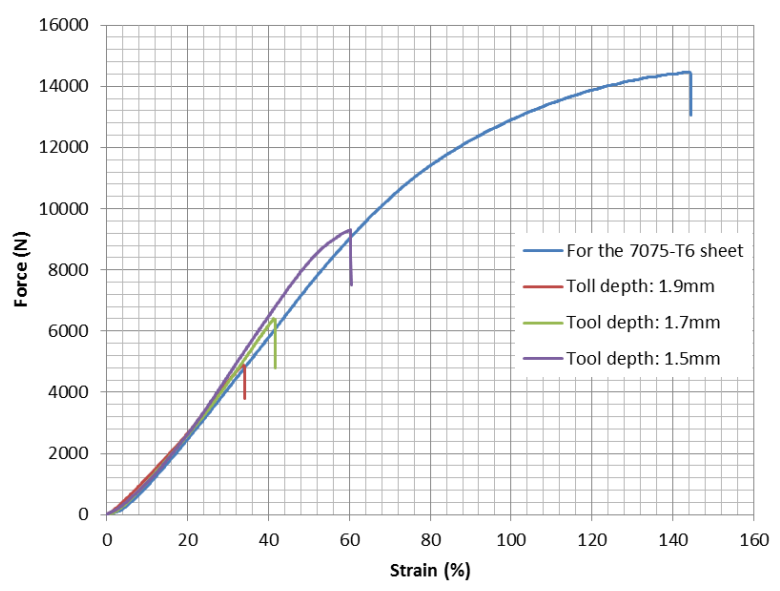

Fig. 8. Sample curves for the stir zone ejection tests for each variant and solid metal sheet.

Average values of the trails are presented in Table 1. The force values are used to determine the degree of weakening that is correlated to the strength of the lap joint subjected to pure shear.

Table 1. The average force values for ejecting the stir zone and the average load carrying capacity of the lap joints made using the RFSSW method depending on tool plunge depth.

\begin{tabular}{|c|c|c|}
\hline $\begin{array}{c}\text { Tool depth } \\
(\mathbf{m m})\end{array}$ & $\begin{array}{c}\text { Maximum force of } \\
\text { the punch test }(\mathbf{N})\end{array}$ & $\begin{array}{c}\text { Shear strength } \\
\text { (N) }\end{array}$ \\
\hline 1.5 & 8970 & 7585 \\
\hline 1.7 & 6125 & 6885 \\
\hline 1.9 & 4824 & 5290 \\
\hline
\end{tabular}


It was expected, that the greater tool plunge depth would result in a stronger joint. Meanwhile, the tendency is opposite: among the analyzed variants the most shallow tool plunge depth of $1.5 \mathrm{~mm}$ resulted in the highest load carrying capacity of the joint was $7585 \mathrm{~N}$. The maximum tool plunge depth of $1.9 \mathrm{~mm}$ resulted in a load carrying capacity of $5290 \mathrm{~N}$.

\section{Conclusions}

The main purpose of tests presented in this paper is presentation and verification of usefulness and reliability of the methodology used to determine the degree of weakening of a weld made using the RFSSW method on its circumference where the structural notches are.

This methodology is offers an original way of conducting experimental test for determining weakening of joints. This can be a complement to static strength testing and constitute a valuable tool in finding optimal process parameters. RFSSW welding, which is a relatively new technology, has a lot of potential and it appears capable of successively replacing the traditional methods of joining thin-walled metal structures in the future.

It is obvious that there is no single universal set of parameters for the RFSSW welding process, their selection always depends on factors such as the type of welded metal, the dimensions of the joints, the coatings used on the plates, etc. And the set of optimal parameters is not only guaranteed by the load capacity of the joint, but also provide a high-quality joint structure, devoid of structural defects, such as structural notches.

The presented research method is focused on fast, cheap and effective recognition of the existence of structural notches in the weld structure. The study shows a correlation between the degree of weakening of the joint and its load capacity, proving that lower the weakening shown by the method, which manifests itself in high value of force of the punch test, translates into higher loading capacity of the joint, this has occured for a 1.5 mm tool plunge depth.

The smallest weakening was demonstrated for the joint welded at the $1.5 \mathrm{~mm}$ tool plunge depth, while the greatest weakness was demonstrated for the weld joint at the tool plunge depth of $1.9 \mathrm{~mm}$. These results coincide with the microstructural analysis of the joints. The larger tool plunge depth produces a larger structural notch due to a greater range of the sleeve path, which manifests itself in greater weakness.

The experiment revealed significant weakening in each variant of the joint due to the structural notch, as well as TMAZ (Thermo-mechanically Affected Zone) which is a natural phenomenon occurring in the welding process. As a reference to the results of the tests, an attempt was made to punch the hole in the intact $1.6 \mathrm{~mm}$ thick 7075 T6 Alclad aluminium alloy sheet using the described tooling. The value for maximum force at punching was 14500 N. For this value, the forces exhibiting weakening of the joint were $62 \%$ for the tool plunge depth $1.5 \mathrm{~mm}$, $42 \%$ for the tool plunge depth $1.7 \mathrm{~mm}$ and $33 \%$ for the tool plunge depth of $1.9 \mathrm{~mm}$.

Obviously, the method does contain a flaw, as the samples analyzed were used having undergone the static shear strength test of the lap joint, which could have weakened the weld area. The research shows that ensuring a pure shearing condition during the static shear strength tests results in the force required for punching through the sheet metal could be used to help determine the welding parameters for RFSSW in order to minimize the structural notch.

The aim of the paper was to present the original experimental method, but it requires further analyzes, conducting further studies for a greater range of welding parameters and correlating the results with microstructures of joints for the considered variants.

\section{References}

1. M. A. Sutton, B. Yang, A. P. Reynolds, R. Taylor, Mater. Sci. Eng. A 323, (2002)

2. S. Zhikang, Y. Xinqi, Z. Zhaohua, C. Lei, L. Tielong, Mater. Des. 44,(2013)

3. Y. Q. Zhao, H. J. Liu, Z. Lin, S. X. Chen, J. C.Hou, Sci. Technol. Weld. Joi. 19, (2014)

4. T.Dursun, C.Soutis, Mater. Des. 56, (2014)

5. P. Briskham, N. Blundell, L. Han, R. Hewitt, K. Young. SAE Technical Paper, (2006)

6. W. Zielecki, A. Kubit, T. Trzepieciński, U. Narkiewicz, Z. Czech. Int. J. Adhes. Adhes. 73, (2017).

7. W. Zielecki, A. Kubit, R. Kluz, T. Trzepieciński. J. Adhes. Sci. Techn. 31, (2016).

8. C. Shilling, J. D. Santos, Method and device for joining at least two adjoining work pieces by friction welding: Patent Application No. US0179682,(2002)

9. S. Venukumar, S. Yalagi, S. Muthukumaran, Trans. Nonferrous Met. Soc. 23, (2013)

10. N. Pathak, K. Bandyopadhyay, M. Sarangi, S.K. Panda, J. Mater. Eng. Perform.22, (2013)

11. Y. Uematsu, K. Tokaji, Sci. Technol. Weld. Joi. 14, (2009)

12. D. H. Choi, B. W. Ahn, C. Y. Lee, Y. M. Yeon, K. U. Song, S. B. Jung, Mater. Trans. 51, (2010)

13. Y.Q. Zhao, H.J. Liu, S.X. Chen, Z. Lin, J.C. Hou. Mater. Des. 62, (2014)

14. R. Kluz,A. Kubit, D. Wydrzyński,Technol. Assembly Automat. 2, (2017)

15. L. Zhengwei, G. Shuangsheng, J. Shude, Y. Yumei, C. Peng Chai, J. Mater. Eng. Perform. 25, (2016)

16. A. Kubit, R. Kluz,T. Trzepieciński, D. Wydrzyński, W.Bochnowski, Arch. Civil Mech. Eng.18, (2018)

17. American Society for Testing and Materials (ASTM). Standard practice for microetching metals and alloys. West Conshohocken: ASTM International (2007). Standard no. E407. 